\title{
Evidence for GABA as a Neurotransmitter in the Leech
}

\author{
Hollis T. Cline \\ Graduate Group in Neurobiology, University of California, Berkeley, California 94720
}

In the leech, Hirudo medicinalis, the inhibitory motor neurons to the longitudinal muscles in the body wall, cells 1 and 2 , are linked via central inhibitory synapses to the excitatory motor neurons innervating the same muscles. Examination of these synapses showed that the inhibitors are GABAergic according to several electrophysiological and pharmacological criteria. Presynaptic release of neurotransmitter during passage of depolarizing current into the inhibitors, as well as direct application of GABA to the excitor cell bodies, hyperpolarizes the postsynaptic excitor. Moreover, both synaptic and extrasynaptic GABA receptors of the excitors are specifically blocked by the GABA antagonist bicuculline methiodide. The inhibitors, dissected from the ganglion and grown in culture, synthesize GABA when exposed to the GABA precursor glutamate, whereas the excitors do not synthesize detectable levels of GABA under these same conditions. The innervation and neurotransmitter sensitivity of the longitudinal muscles in the body wall of the glossiphoniid leeches Haementeria ghilianii and $H$. officinalis were examined in order to determine if the inhibitory neurotransmitter at the neuromuscular junction is GABA. Individual muscle fibers are innervated by both inhibitory and excitatory motor neurons in a manner such that the inhibitory and excitatory nerve terminals and neurotransmitter receptors are spatially and electrically separate. Intracellular recordings taken from the muscle fibers reveal a resting potential of about $-70 \mathrm{mV}$. The amplitude of the spontaneous inhibitory junctional potentials (IJPs) falls to zero at a polarization of about $-65 \mathrm{mV}$ and reverses in sign at the normal resting potential. Application of GABA to inhibitory junctional sites results in an increased conductance of the muscle fiber membrane and a polarization with a reversal potential of about $-65 \mathrm{mV}$. Bicuculline methiodide blocks reversibly the GABA response and all spontaneous IJPs, without blocking the spontaneous excitatory junctional potentials (EJPs) recorded from the excitatory junctional sites.

Inhibitory synaptic connections have been found to play an essential role in the generation of the rhythmic motor patterns in the leech (Stent et al., 1978, 1979). GABA, whose inhibitory synaptic action has been documented in other invertebrates, notably in another annelid, the earthworm (Ito et al., 1969) and in crustaccans (Otsuka, 1976), is a likely candidate for the neurotransmitter at some of these synapses. The segmental ganglion of the leech has the capacity to synthesize GABA from the precursor glutamate (Cline, 1983; Sargent, 1977), and approximately 35 neurons per ganglion possess a high-affinity uptake system for GABA (Cline, 1983), diagnostic of GABAergic neu-

\footnotetext{
Received July 8, 1985; revised Apr. 11, 1986; accepted Apr. 17, 1986.

I thank Gunther Stent for his advice and guidance, and William Kristan and John Miller for allowing me to carry out part of this work in their laboratories. I am indebted to Janis Weeks, William Roherts, and Roherto Malinow for helpful comments on the manuscript. This work was supported by NIH Training Grant GM 07048 and by NIH Research Grant NS 12818 .

Correspondence should be addressed to Hollis T. Cline, Department of Biology, P.O. Box 6666, Yale University, New Haven, CT 06511

Copyright (C) 1986 Society for Neuroscience $0270-6474 / 86 / 102848-09 \$ 02.00 / 0$
}

rons (Schousboe, 1981). In the hirudinid leech, Hirudo medicinalis, two bilateral pairs of inhibitory motor neurons, or inhibitors, to the longitudinal muscles, designated cells 1 and 2 (Ort et al., 1974; Stuart, 1970), seem likely to be GABAergic because they are among the neurons that take up GABA with high affinity (Cline et al., 1985).

Within each of the iterated segmental ganglia of the ventral nerve cord, the inhibitors to the longitudinal muscles form central inhibitory synapses with excitors to the same muscle fibers (Ort et al., 1974). The neuromuscular transmission linking the excitors to the longitudinal muscles is mediated by ACh (Kuffler, 1978; Sargent, 1977), but the identity of the inhibitory transmitter has not been established (Muller et al., 1981). Therefore, the central and peripheral targets of the inhibitors to the longitudinal muscles were examined to determine whether neurotransmission between the inhibitors and their targets is mediated by GABA. Leeches from 2 genera were used for these studies: The central synapses between the inhibitors and excitors were examined in the hirudinid leech, Hirudo medicinalis, because the neurons of interest and their synaptic connections have been described previously (Granzow et al., 1985; Ort et al., 1974; Stuart, 1970); the neuromuscular synapses were examined in the glossiphoniid leeches, Haementeria ghilianil and $H$. officinalis, because it is easier to visualize and record from individual muscle fibers and regions of neuromuscular contact.

In Hirudo, the bilaterally paired cell 1 innervates the longitudinal musculature in the dorsal body wall as well as the bilaterally paired excitatory motor neurons, or excitors-designated cells 3 and 5 (Ort et al., 1974; Stuart, 1970)-which innervate the same longitudinal muscles. Similarly, cell 2 innervates the longitudinal muscles in the ventral body wall and the bilaterally paired excitors that innervate the ventral musculature-designated cell 4 (Ort et al., 1974; Stuart, 1970). Both cells 1 and 2 innervate the $L$ motor neuron, which provides excitatory synaptic input to both dorsal and ventral longitudinal muscles (Ort et al., 1974; Stuart, 1970). The inhibitors and excitors of the longitudinal muscles can be unambiguously identified in Hirudo medicinalis, according to the position of their cell bodies in the segmental ganglion, their synaptic connections, the amplitude and shape of the action potentials recorded in their cell bodies, and the pattern of the axonal projections in identified peripheral nerves (Granzow et al., 1985; Ort et al., 1974; Poon, 1976; Stent et al., 1978; Stuart, 1970).

The results presented in this paper correspond with the physiological criteria that a candidate substance must meet in order to qualify as a neurotransmitter. The central synaptic interactions between the inhibitors and excitors of Hirudo and the nerve-muscle interactions in the periphery of Haementeria are described. The application of exogenous GABA to the excitor or muscle fiber is shown to mimic their synaptic response, as regards membrane polarization, increase in membrane conductance, and reversal potential. The postsynaptic GABA receptors are shown to be pharmacologically similar to previously characterized GABA receptors, in that they are reversibly blocked by bicuculline methiodide, a stable analog of the common GABA 
antagonist, bicuculline (Pong and Graham, 1972). Finally, individual inhibitors isolated from the ganglion and grown in culture are shown to have the capacity to synthesize GABA from glutamate, which several other identitied leech neurons are shown to lack.

\section{Materials and Methods}

\section{The CNS}

\section{Electrophysiology}

Desheathed midbody ganglia dissected from Hirudo medicinalis were pinned dorsal side up in a Sylgard dish (Dow-Corning) equipped with a gravity-fed perfusion system. The ganglia were continually perfused with normal leech Ringer's solution modified from Nicholls and Purves (1970) as follows: $115 \mathrm{~mm} \mathrm{NaCl} ; 4 \mathrm{mM} \mathrm{KCl} ; 1.8 \mathrm{mM} \mathrm{CaCl}_{2} ; 10 \mathrm{~mm}$ HEPES, pH 7.4 with $\mathrm{NaOH}$, or with Ringer's solution supplemented with $5 \mathrm{mM} \mathrm{CaCl}_{2}$ and $5 \mathrm{mM} \mathrm{MgCl}_{2}$ to minimize contractions of the muscle fibers investing the nerve cord. Bicuculline methiodide (Pierce Biochemical) was prepared as a stock solution $\left(10^{-4} \mathrm{M}\right)$ in Ringer's solution and diluted immediately prior to use. The stock solution was kept for no longer than $2 \mathrm{~d}$. GABA, bicuculline methiodide, and other candidate GABA antagonists were presented to the preparation and removed via a gravity-fed perfusion system. Complete exchange of the bath took about 1 min

The electrophysiological procedures used for recording and stimulating neuronal activity were as previously described (Kristan et al., 1974; Ort et al., 1974). The ganglia were viewed under dark-field illumination, and intracellular recordings were taken from the cell bodies of neurons by means of glass microelectrodes of 30-50 M $\Omega$ resistance filled with $4 \mathrm{M}$ potassium acetate; extracellular recordings from segmental nerve roots were taken with glass suction electrodes. Amplified recordings were displayed on a multiple-trace storage oscilloscope and pen recorder, and stored on magnetic tape.

\section{Neurotransmitter application}

In addition to bath application, GABA was applicd focally to ncuronal cell bodies and to the ganglionic neuropil from a micropipette attached to a pressure ejection device. The pipette was filled with a filtered mixture of GABA $\left(10^{-4} \mathrm{M}\right)$ in Ringer's solution and $0.5 \%$ Fast green dye (Chroma-Gesellschaft). The pipette tip was broken on a shard of glass and positioned within $5 \mu \mathrm{m}$ of the neuronal cell body whose electrical activity was being recorded. For GABA application to the neuropil, the pipette was advanced directly into the neuropil while recording intracellularly from an excitor or inhibitor cell body.

\section{Determination of the reversal potential}

Hyperpolarizing current was passed into the excitor in the form of a ramp (see Fig. 6) before and after focal GABA application to the excitor cell body. Comparison of the effect of current injection in the presence and absence of GABA shows that the membrane is more polarized above and less polarized below the reversal potential of the GABA reponse, at any given level of the current ramp. Consequently, when the 2 voltage traces obtained in the presence and absence of GABA are superimposed, they cross at the reversal potential for the GABA response.

An alternate means of analyzing data from these experiments is to display them as an $I / V$ curve. Rapid ( $300 \mathrm{msec}) 3 \mathrm{nA}$ current ramps injected into the excitor hyperpolarize repeatedly the cell membrane well below $E_{\mathrm{CI}}$ (see Fig. 7). The membrane potential change produced by each ramp may be used to generate an $I / V$ curve. The linear portions of the $2 \mathrm{I} / \mathrm{V}$ curves (taken at membrane potentials more positive than that at which anomalous rectification is activated) were extrapolated to their point of intersection. The membrane potential corresponding to the point of intersection is the reversal potential of the GABA response.

The $I / V$ curves are, in fact, loops, because the lower part of the loop is generated from the hyperpolarizing phase and the upper part is from the repolarizing phase of the current ramps. Each loop exhibits a hysteresis between the hyperpolarizing and repolarizing phases of the curve, indicating a greater net conductance as the membrane repolarizes. Furthermore, at high strengths of injected hyperpolarizing current both sets of $I / V$ curves overlap and display an increased conductance represented by the higher slope of the curve. Both of these effects are probably due to anomalous rectification, which apparently dominates the other con- ductances at membrane potentials below $-50 \mathrm{mV}$. To account for the hysteresis, it is likely that, comparable to other membranes that display anomalous rectification (Hagiwara and Jaffe, 1979): (1) the voltagesensitive channels remain open at voltages more depolarized than those at which they are activated, and (2) the time constant of their closing is slow $(0.5 \mathrm{sec})$ so that some channels that opened during the hyperpolarizing ramp are still open during the depolarizing ramp. Accordingly, the lower part of each loop from the hyperpolarizing phase of the current ramp was used to construct the intersection of the extrapolated linear portion of the $I / V$ curves.

\section{GABA synthesis in cultured neurons}

Leech neurons were cultured according to the method of Pierre Drapeau (personal communication). Desheathed abdominal ganglia were incubated at $20^{\circ} \mathrm{C}$ for $1-1.5 \mathrm{hr}$ in $2 \mathrm{mg} / \mathrm{ml}$ Collagenase/Dispase (Boehringer/ Mannheim) made up in L-15 medium (Gibco) supplemented with fetal calf serum ( $2 \%$; Sterile Systems, Inc.), glucose (0.6\%), and gentamycin (Garamycin; $10 \mathrm{mg} / 100 \mathrm{ml}$ ). The ganglia were rinsed free of enzyme, and selected neurons identified by their cell body size and location in the ganglion were isolated with a fire-polished microelectrode. Isolated neurons were plated in polylysine-coated (Sigma, $M_{\mathrm{r}} 15,000-30,000$ ) $10 \mu 1$ wells of microtest plates (Faicon) and grown at room temperature for 4-5 $\mathrm{d}$ before their ability to synthesize GABA was assayed.

The capacity of isolated neurons to synthesize GABA from the precursor glutamate was determined as follows. The culture medium was removed and replaced with medium supplemented with $10 \mathrm{~mm}$ glutamate, $0.01 \mathrm{~mm}{ }^{3} \mathrm{H}$-glutamate $(23.3 \mathrm{Ci} / \mathrm{mmol}$; New England Nuclear), and $20 \mathrm{~mm}$ phosphate buffer to maintain physiological $\mathrm{pH}$. Following $3 \mathrm{hr}$ incubation at room temperature, the incubation solution and the isolated neurons were applied to chromatography paper along with $5 \mu \mathrm{l}$ each of glutamate and GABA standard solutions $(20 \mathrm{mg} / \mathrm{ml})$. The glutamate and GABA were separated electrophoretically, visualized, and assayed as described previously (Cline, 1983). The incubation medium was subjected to high-voltage electrophoresis to check for contamination of glutamate degradation products which coelectrophorese with GABA. The resolution of the assay was about $2.3-2.5$ pmol.

\section{The neuromuscular junction}

To examine the electrophysiological characteristics of neuromuscular synapses, a body wall preparation from either Haementeria ghilianii or $H$. officinalis consisting of several segments of ventral body wall and their innervating ganglia was used. "First fed" and "second fed" leeches, categorized according to the number of meals they have consumed, were used for these experiments (Sawyer et al., 1976). The body wall preparation was pinned to a Sylgard dish and continually perfused with Haementeria Ringer's solution $-130 \mathrm{~mm} \mathrm{NaCl} ; 8 \mathrm{mM} \mathrm{KCl} ; 1.8 \mathrm{~mm}$ $\mathrm{MgCl}_{2} ; 1.8 \mathrm{~mm} \mathrm{CaCl}_{2} ; 10 \mathrm{~mm}$ HEPES, pH 7.6 with $\mathrm{NaOH}$ (Kramer and Goldman, 1981)-supplemented with $5 \mathrm{~mm} \mathrm{CaCl}_{2}$ and $5 \mathrm{~mm} \mathrm{MgCl}_{2}$ to minimize muscle contractions.

The procedures for recording intracellularly from the muscle fibers and applying neurotransmitters and pharmacological agents were the same as those used for the CNS, as described above. In Haementeria, the cell bodies of the inhibitors to the longitudinal muscles, the homologs to cells 1 and 2 in Hirudo, have not been identified. Therefore, the spontaneous activity in the inhibitors was relied upon to provide the endogenous inhibitory transmitter, rather than current injection into the presynaptic neurons.

\section{Results}

\section{Inhibitor-excitor synapse}

For all pairs of neurons studied, passage of depolarizing current into an inhibitor (cell 1 or 2) caused the postsynaptic excitor (cell 3, 4, 5, or L) to hyperpolarize below the action potential threshold and to exhibit an increase in membrane conductance (Fig. 1). Action potentials in the motor neurons do not invade the cell body and are recorded intraccllularly as small (1-5 mV) sharp spikes. Furthermore, a one-for-one correlation of action potentials in the inhibitor with IPSPs in the postsynaptic excitor is not seen because the combined effects of graded release of neurotransmitter by the inhibitors and the location of the inhibitory synaptic sites in the elcctrotonically distant neuropil (Granzow et al., 1985). Extracellular recordings from the peripheral 
A

cell 3

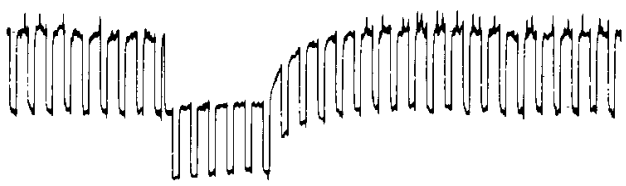

DP nerve

PP nerve

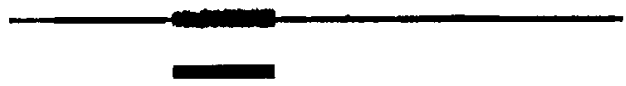

B

cell 5

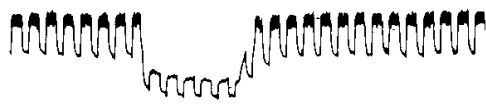

PP nerve

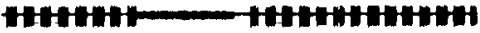

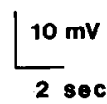

Figure 1. Synaptic response of the excitors, cell $3(A)$ or cell $5(B)$, to passage of depolarizing current into the presynaptic inhibitor cell 1. Intracellular recordings are taken from the excitor and extracellular recordings are taken from the dorsal posterior $(D P)$ and posterior posterior $(P P)$ nerves (Ort et al., 1974). Cell 3 projects into the periphery via the contralateral DP nerve, and cells 1 and 5 project via the contralateral PP nerve. The membrane conductance of the excitors was monitored by periodic injection of brief hyperpolarizing current pulses. Injection of depolarizing current into the inhibitors (bar) causes them to generate impulses, as indicated by the small-amplitude spikes seen in the extracellular record taken from the PP nerve. The amplitude of the injected current was the minimum that would evoke a train of action potentials, and ranged from 0.5 to $2.0 \mathrm{nA}$. $A$, Cell 3 hyperpolarizes while cell 1 is depolarized and generating action potentials (seen in the PP nerve trace). Once current passage into cell 1 is terminated, cell 1 ceases impulse production, and cell 3 recovers its original membrane potential and generates action potentials, which match one-for-one in the intracellular and extracellular (DP nerve) records. $B$, Intracellular stimulation of cell 1 causes a membrane hyperpolarization and conductance increase in cell 5 , as indicated both in the extracellular record by the largeamplitude spikes in the extracellular records taken from the PP nerve and in the intracellular record. The small-amplitude spikes attributable to cell 1 action potentials appear in the PP record only during the period of current injection into cell 1 . In this case, the excitor was depolarized by the injection of a steady depolarizing current to amplify the synaptic response.

nerves containing processes from the inhibitor and excitor show that the inhibitor was generating impulses and the excitor was inactive during current passage (see Fig. 1 legend for details). The resting membrane potential, membrane conductance, and impulse frequency of the excitor are restored when current passage into the inhibitor ceases. The inhibition of the excitors is blocked by the addition of $10 \mathrm{mM} \mathrm{MgCl}_{2}$ to the bathing solution, indicating that the inhibition is mediated by a neurotransmitter released by a calcium-dependent mechanism (Baylor and Nicholls, 1969).

Passage of hyperpolarizing current into the inhibitors results in the depolarization of the excitors by $2-3 \mathrm{mV}$ (data not shown), suggesting the removal of a tonic source of inhibitory input. Such depolarization of the excitors is observed even if the inhibitor is not generating action potentials prior to the passage
+ GABA

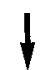

cell 1

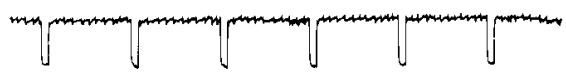

PP nerve

cell 3

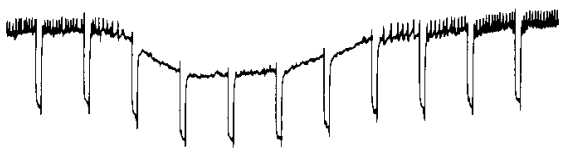

DP nerve

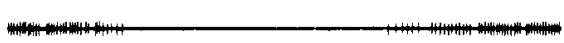

cell 5

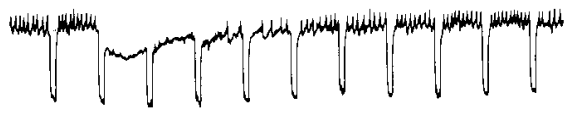

PP nerve

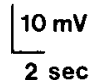

Figure 2. The excitors, cells 3 and 5, respond to focal application of GABA to the cell hody ( $n=15$ and 12 , respectively), whereas the inhibitor, cell 1 , does not $(n=5)$. Intracellular recordings from the inhibitor and excitor cell bodies and extracellular recordings from the peripheral nerves containing their axons. Impulse generation in the excitors, as manifest in the extracellular nerve recordings, ceases at the onset and resumes upon termination of the GABA pulse. The GABA responses in cell 3 and cell 5 are different because the sirength of the response increases with the amount of GABA ejected from the pipette and decreases with the distance of the pipette tip from the cell body.

of hyperpolarizing current and indicates nonspiking release of transmitter (Granzow et al., 1985).

\section{Application of $G A B A$}

Application of GABA, either by addition to the bathing solution or by focal pressure ejection from a micropipette positioned directly over the cell body, hyperpolarizes the excitors and increases their membrane conductance (Fig. 2), thus mimicking the effects of depolarizing current injection into the inhibitor. The concentration of $\mathrm{MgCl}_{2}$ in the Ringer's solution was elevated to $10 \mathrm{~mm}$ to suppress synaptic transmission (Baylor and Nicholls, 1969). Focal application of GABA to the inhibitors (cells 1 and 2) either causes no detectable change in membrane properties (Fig. 2) or a slight hyperpolarization $(2-3 \mathrm{mV}$ ) in cell 2 (data-not shown), suggesting that cell 2 may respond to GABA.

Focal GABA application to regions of the neuropil corresponding to the trajectory of the major neurite of the excitor (Ort et al., 1974) also produces a hyperpolarization and conductance increase of the excitor membrane in the presence of elevated $\mathrm{MgCl}_{2}$ (Fig. 3). Application to regions of the neuropil that do not include any portion of the excitor does not elicit any change in membrane potential or conductance. Application of Ringer's solution containing only Fast green dye does not elicit any change in membrane properties.

\section{$G A B A$ antagonists}

Bicuculline methiodide $\left(5 \times 10^{-5} \mathrm{M}\right)$, a stable analog of bicuculline, reversibly blocks both the hyperpolarization and the 


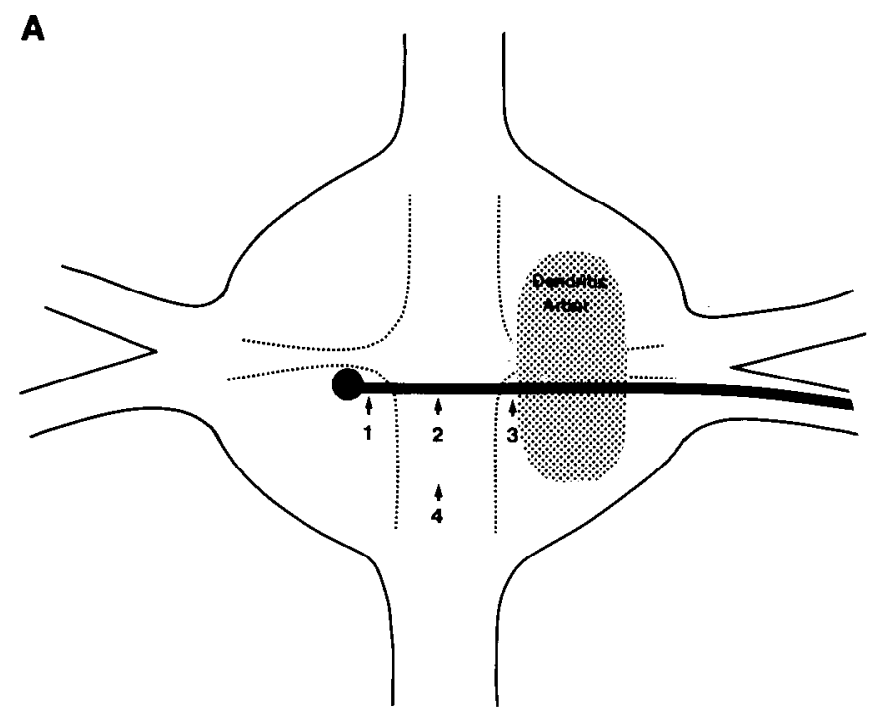

B

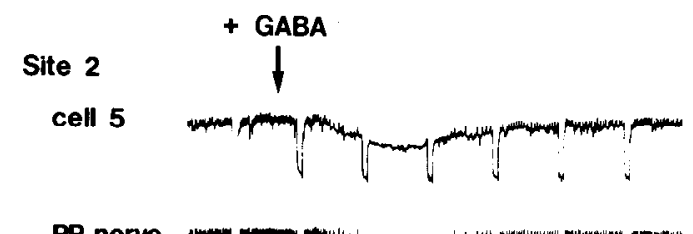

Site 4

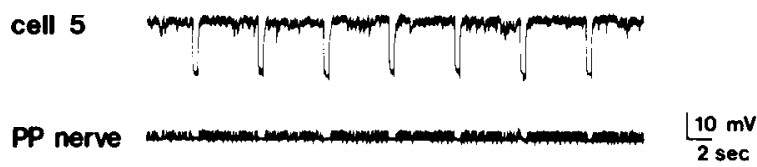

Figure 3. Excitors hyperpolarize when GABA is applied to some regions of the neuropil, but not to others. $A$, Schematic representation of the morphology of cell 5 , and the 4 sites in the neuropil to which GABA was applied. $B$, Responses recorded intracellularly from cell 5 and extracellularly from the PP nerve during GABA application to the neuropil. Numbers correspond to the site on the diagram where the GABA pipette was placed in the neuropil. Responses from sites 1 and 3 were similar to the response from site 2 , and therefore are not shown $(n=$ 3).

conductance increase normally elicited by focal application of GABA to the excitor cell body (Fig. 4). In some preparations, focal GABA application elicits a small $(2 \mathrm{mV})$ depolarization in the presence of bicuculline methiodide (Fig. 4). The inhibitory synapses of cell 1 onto cells 3,5 , and $\mathrm{L}$, and from cell 2 onto cell 4 are also reversibly blocked by bicuculline methiodide $(5 \times$ $10^{-5} \mathrm{M}$; Fig. 5). The minimal concentration of bicuculline methiodide capablc of blocking the GABA or synaptic response is $10^{-6} \mathrm{M}$, and concentrations higher than $5 \times 10^{-4} \mathrm{M}$ block all activity recorded from cell bodies and nerve roots. Extracellular recordings from nerve roots show that the inhibitors have the capacity to generate action potentials in the presence of bicuculline. To control for the possibility that the postsynaptic excitor happened to be at the reversal potential of the IPSP, in which case stimulation of the inhibitor would not result in a change in membrane potential, the excitor was depolarized to its threshold for generating action potentials, while stimulating

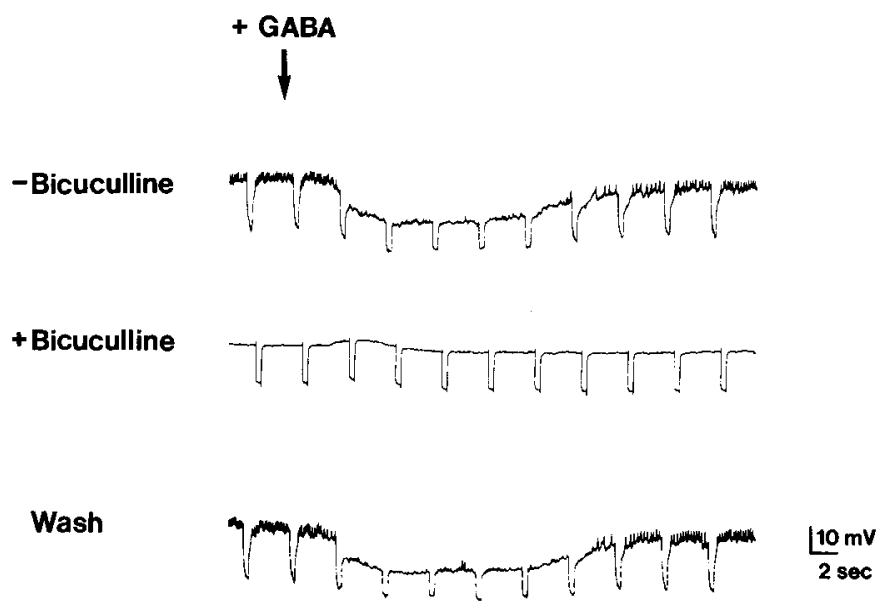

Figure 4. Bicuculline methiodide $\left(5 \times 10^{-5} \mathrm{M}\right.$ in the bathing solution) reversibly blocks the response to GABA focally applied to the excitor cell body. Continuous intracellular recordings taken from cell 4 show that the GABA-elicited membrane hyperpolarization and increased conductance are blocked by bicuculline and is restored upon washing it out $(n=5)$.

the inhibitor. Under these conditions, synaptic transmission is still blocked in the presence of bicuculline (Fig. 5). This conclusion was supported by the observation that the membrane conductance of the postsynaptic excitors does not increase in the presence of bicuculline.

To determine whether bicuculline methiodide specifically blocks the inhibitory synapses from cells 1 and 2 onto the excitors, without interfering with other synaptic inputs onto these same neurons, several monosynaptic excitatory inputs onto the excitors were examined in the presence of bicuculline. For example, the monosynaptic excitatory synapse from cell 208 , an unpaired interneuron belonging to the swim motor pattern generator circuit (Weeks, 1982), onto the excitor cell 5 persists in the presence of sufficient bicuculline to block the inhibitory synapse from cell 1 (Fig. 5B). Similarly, the excitatory input from cell $\mathrm{P}$ to cell $\mathrm{L}$ (Muller et al., 1981) persists in the presence of bicuculline (data not shown). As a further indication that bicuculline methiodide does not interfere with neuronal functions, many spontaneous EPSPs and IPSPs are recorded from motor neurons and sensory neurons in the presence of bicuculline methiodide. Bicuculline methiodide $\left(5 \times 10^{-5} \mathrm{M}\right)$ does not cause obvious changes in the level of spontaneous activity of either the excitors or inhibitors, nor in the nerve roots, al though continuous intracellular recordings from the excitors while bicuculline was introduced to the bath reveal that in some preparations the excitors depolarize by $2-3 \mathrm{mV}$ in the presence of bicuculline methiodide, consistent with the idea suggested above that the inhibitory synapse displays tonic release of GABA.

\section{Determination of the reversal potential}

The presence of anomalous rectification in the membranes of the excitors prevents the determination of the reversal potential by the standard techniques (Nicholls and Wallace, 1978). Therefore, a new method was devised that allows one to determine the reversal potential of a channel despite the presence of a large anomalously rectifying conductance. This method relies on 2 observations: (1) In the presence of GABA the membrane potential will reflect the contribution of the GABA-activated channels to the total membrane conductance, and (2) the inhibitory response to GABA may be recorded from the excitors at membrane potentials more positive than that at which the anomalous rectification is activated (about $-50 \mathrm{mV}$ ). According to the first observation, the reversal potential of the GABA response may be determined by comparing the total membrane conductance 
A

\section{-Bicuculline}

cell 5

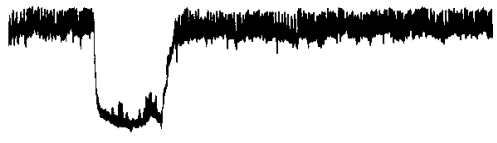

PP nerve

\section{+Bicuculline}

cell 5

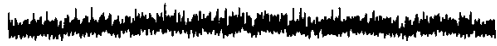

PP nerve

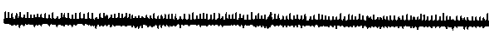

Wash

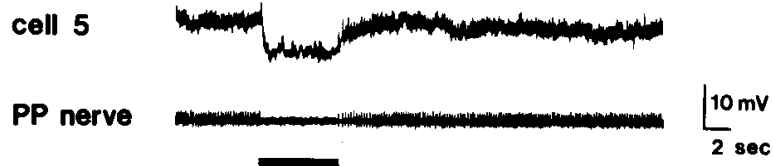

B

\section{+ Bicuculline}

cell 208

cell 5

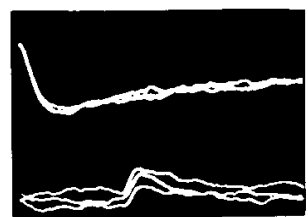

Figure 5. Bicuculline methiodide $\left(5 \times 10^{-5} \mathrm{M}\right)$ reversibly blocks the synapse from the inhibitor cell 1 onto the excitor cell 5 , without interfering with either the spontancous impulsc activity in the excitor or with specific excitatory inputs to it from another source. $A$, Intracellular recordings from cell 5 and extracellular recordings from the PP nerve. Prior to the addition of bicuculline, cell 5 was depolarized and generating action potentials, seen in the PP nerve record as large-amplitude spikes. Impulse activity is depressed by stimulating the inhibitory synapse by depolarizing current injection into cell 1 . Action potentials generated in cell 1 are detectable in the PP nerve recording as small-amplitude spikes during the stimulation period (bar). Cell 5 continues to generate action potentials after the addition of bicuculline methiodide to the bathing solution, seen in both the intracellular and extracellular recording, but the synaptic response is blocked. The synaptic response returns after the bicuculline is washed out of the bathing solution.

in the presence and absence of GABA. An example of this type of experiment is shown in Figure 6. A ramp of hyperpolarizing current injected into cell 3 in the absence of GABA caused the cell to hyperpolarize by about $45 \mathrm{mV}$, to $-83 \mathrm{mV}$, well below $E_{\mathrm{Cl}}$ (Sawada and Coggeshall, 1976). GABA was applied focally to the excitor cell body and the initial membrane hyperpolarization and conductance increase in the excitor cell body due to GABA application were recorded prior to the injection of the hyperpolarizing current ramp. Superimposing the voltage traces from the responses in the presence and absence of GABA (Fig. 6 ) demonstrates that the 2 traces cross in a range of membrane potentials between -59 and $-68 \mathrm{mV}$.

By injecting rapid ramps of hyperpolarizing current into the excitor cell body prior to and during focal GABA application,
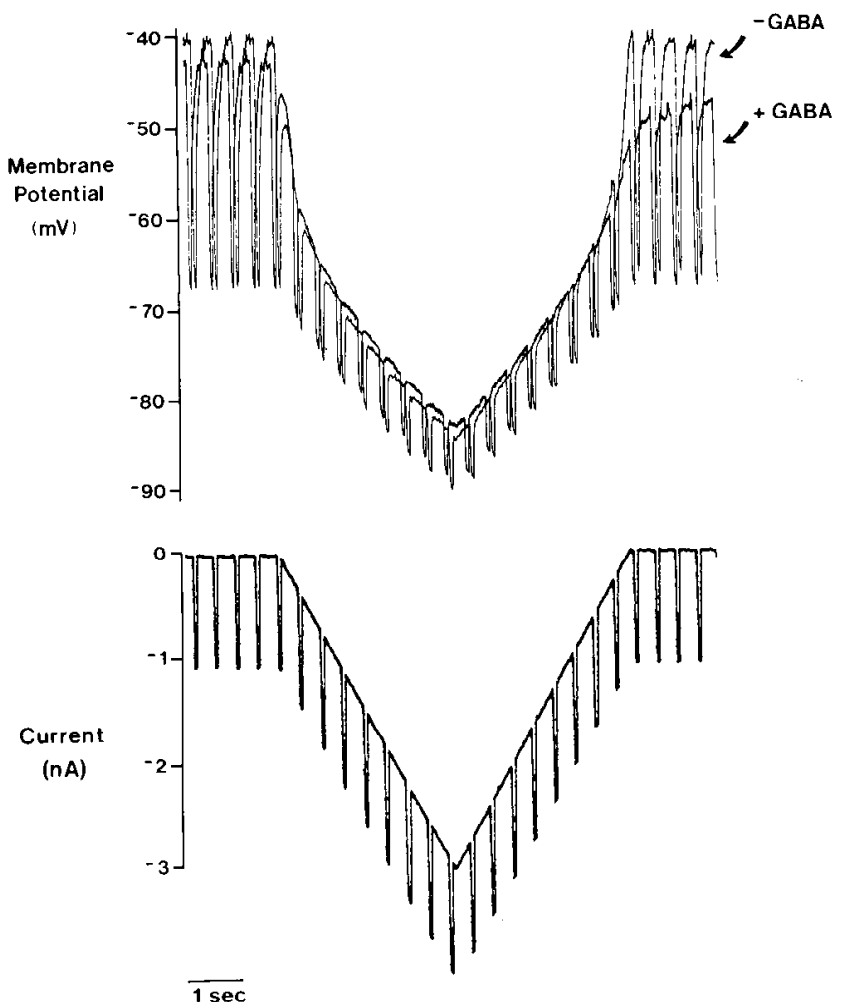

Figure 6. Estimation of the reversal potential of the GABA response. A slow ramp of hyperpolarizing current, peaking at $3 \mathrm{nA}$, plus $-1 \mathrm{nA}$ current pulses, is injected into the excitor cell 3 , causing it to hyperpolarize the membrane to about $-83 \mathrm{mV}$, below $E_{\mathrm{Cl}}$. GABA was applied focally to the excitor cell body in the interval between the 2 voltage traces were taken, so that the membrane potential hyperpolarization and conductance increase in the "+ GABA" trace indicate that the excitor has started to respond to GABA before the current ramp was injected. The membrane potential response in the presence of GABA is superimposed on the response in its absence. The current trace is on the bottom and the voltage traces are on top. The reversal potential of the GABA response is the membrane potential corresponding to the point where the 2 voltage traces cross. According to this method, the reversal potential lies between -58 and $-68 \mathrm{mV}(n=4)$.

$2 I / V$ curves may be generated, as shown in Figure 7 . The reversal potential of the GABA response may be obtained by extrapolating from the initial linear portion of the lower phase of the loops, as described in Materials and Methods. Their intersection reverses the potential of the GABA response in the range of -64 to $-62 \mathrm{mV}$, i.e., near $E_{\mathrm{Cl}}$. Although the data presented here suggest that the GABA response is mediated by a chloride conductance, it has not been ruled out that the IPSP may be due to a combination of chloride and potassium conductances.

In addition to establishing the reversal potential of the GABA response, these experiments reveal a strong voltage-dependent ion channel that appears to be an inward or anomalous rectifier (Hille, 1984; Latorre et al., 1984). During the hyperpolarizing ramp in Figure 6 , the net membrane conductance increased by approximately $70 \%$, as revealed by the decreased voltage deflection due to the $-1 \mathrm{nA}$ pulses. The net increase in conductance attending hyperpolarization, or anomalous rectification, may be due to voltage-sensitive $\mathrm{K}^{+}$channels, which are activated at polarizations greater than about $-50 \mathrm{mV}$ (i.e., beyond the normal resting potential of the excitors) and once activated remains active at voltages less polarized than those at which it is activated. 


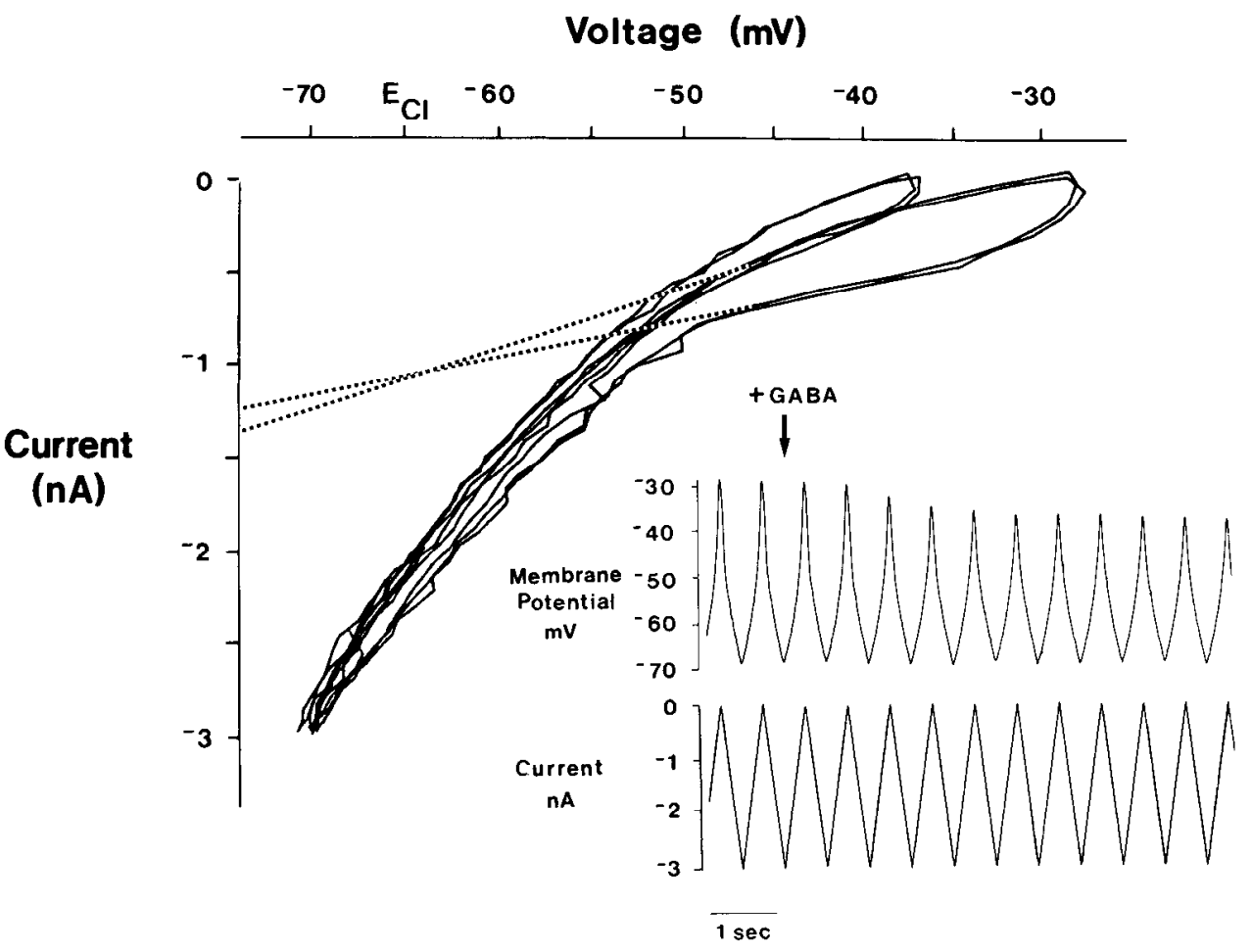

Figure 7. Estimation of the reversal potential of the GABA response from $2 \mathrm{I} / \mathrm{V}$ curves, the first obtained prior to GABA application and the second during the GABA response. The membrane hyperpolarization and increase in conductance in response to addition of GABA are reflected, respectively, by the shift along the voltage axis of the point at which no current is injected, and the steepening slope of the curves. The reversal potential for the GABA response is determined by extrapolating the initial linear portions of the curves to their point of intersection at about $-64 \mathrm{mV}$ $(n=4)$. Inset: GABA is applied focally to the cell 5 soma while rapid 3 nA ramps of hyperpolarizing current are injected into the cell. The hyperpolarizing current drives the membrane potential to about $-70 \mathrm{mV}$, below $E_{\mathrm{CI}}$. Cell 5 had been depolarized to about $-30 \mathrm{mV}$ by the injection of DC current. The pair of $I / V$ curves is derived from the inititial and final portions of the trace.

\section{Neurotransmitter synthesis by individual inhibitors}

The following neurons were assayed for their capacity to synthesize GABA: the putative GABAergic inhibitors, cells 1 and 2; the putative cholinergic excitors, cells 3 and 4 (Kuffler, 1978; Sargent, 1977); the mechanosensory P neurons, whose transmitter is unknown; and the serotonergic Retzius cells. The inhibitors, cells 1 and 2, have the capacity to synthesize an average of $5.6 \pm 0.8 \mathrm{pmol} \mathrm{GABA} /$ neuron over a $3 \mathrm{hr}$ exposure to 10 mM glutamatc $(n=20)$. Surprisingly, the Retzius cells have the capacity to synthesize $8.8 \pm 0.9 \mathrm{pmol} \mathrm{GABA} /$ neuron $(n=4)$. Assuming that the neuronal cell bodies are spherical with cell diameters of $40 \mu \mathrm{m}$ for the inhibitors and $70 \mu \mathrm{m}$ for the Retzius cells (Muller et al., 1981), the intracellular concentrations of GABA/neuron are about $170 \mathrm{pM}$ GABA/inhibitor and about 50 pм GABA/Retzius cell. In contrast, the excitors and the mechanosensory P neurons synthesize no detectable GABA. In such cases where single neurons were found to have no detectable GABA synthesis capacity, 5 neurons were pooled and the pooled sample was assayed in an attempt to accumulatc dctectable quantities of newly synthesized GABA. Nevertheless, no GABA synthesis capacity greater than the blank was obtained for the excitors or mechanosensory P neurons.

\section{The neuromuscular junction}

\section{Electrophysiology}

In young Haementeria, the bundles of longitudinal fibers are relatively free of investing non-muscle cells, and the ventral skin is sufficiently transparent so that, under dark-field illumination, individual muscle fibers and fine-caliber nerve bundles branching off of the major nerve bundles can be seen. In order to record from fibers at sites very near to neuromuscular junctions, the segmental nerves were followed visually from the ganglion into the body wall. Often, small branches of the nerve could be seen splitting off the major branch toward a single muscle fiber bundle. Intracellular recordings obtained by penetrating muscle fibers in these regions are rich in spontaneous excitatory or inhibitory junctional potentials (EJPs or IJPs), such as those shown in Figure 8. Sites from which spontaneous EJPs are recorded are more prevalent than sites from which spontaneous IJPs are recorded. There are also sites along the fibers from which either no spontaneous junctional potentials or a mixture of IJPs and EJPs is recorded. The amplitudes of EJPs and IJPs recorded from a junctional region of the muscle fiber range from 2 to 8 $\mathrm{mV}$ and rise quickly from the resting potential. In addition, more slowly rising junctional potentials can be seen, which evidently originate at more distant junctional sites.

The muscle fibers normally maintain a resting potential of about -70 to $-80 \mathrm{mV}$. The IJPs reverse in sign when the resting potential exceeds $-65 \mathrm{mV}$ and are therefore depolarizing at the resting potential. Even when the IJPs are reversed in sign, they can be distinguished from EJPs by their relatively rapid recovery time (for instance, compare the top and bottom traces in Fig. 8) and by the rapid increase of their amplitude as the membrane is hyperpolarized below the reversal potential.

\section{Application of neurotransmitters}

Focal application of GABA to muscle fiber sites rich in spontaneous IJPs results in an increase in membrane conductance and polarization (Fig. 9), whereas GABA application to sites rich in EJPs results in no apparent change in membrane electrical properties. The direction of the change in membrane polarization in response to GABA application depends on the resting potential of the fiber; fibers with a resting polarization more than $-65 \mathrm{mV}$ depolarize, while those with resting polarization less than $-65 \mathrm{mV}$ hyperpolarize. Furthermore, the duration of the GABA response of the fiber increases with longer applications of GABA, and does not show any desensitization of the GABA receptors, such that the changes in membrane properties may be maintained throughout a continuous $2 \mathrm{~min}$ application of GABA (Fig. 9, top trace).

Focal application of ACh to sites of the muscle from which EJPs are recorded results in a membrane depolarization culminating in single or multiple overshooting action potentials and muscle fiber contraction (data not shown). Application of ACh to sites rich in IJPs yields no immediate polarization of the muscle membrane potential. Following a brief delay, during 


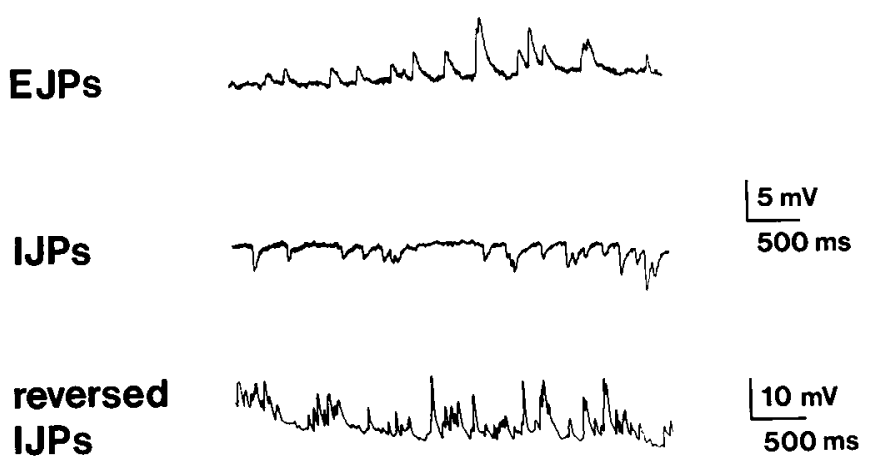

Figure 8. Spontaneous activity recorded from one region of a muscle fiber rich in spontaneous EJPs (top trace) and another region rich in spontaneous IJPs (middle trace). The resting potential of the muscle fibers often exceeds $-75 \mathrm{mV}$. The spontaneous IJPs flatten at $-65 \mathrm{mV}$ and are reversed in sign at more negative potentials (bottom trace).

which ACh presumably diffuses to nearby ACh receptors, the fibers depolarize and contract slowly. The fast and slow contractions probably reflect differences in ACh concentrations at the excitatory neuromuscular junctions. Application of Ringer's solution containing only Fast green dye does not alter the membrane potential or cause contraction of the muscle fibers.

\section{GABA antagonists}

The presence of bicuculline methiodide $\left(5 \times 10^{-5} \mathrm{M}\right.$ in the bathing solution) reversibly blocks the changes in membrane polarization and conductance normally produced by application of GABA (Fig. 9), as well as all spontaneous IJPs, without affecting the frequency of spontaneous EJPs. By contrast, picrotoxin $\left(10^{-4}\right.$ M), a GABA antagonist of inhibitory neuromuscular transmission in the earthworm (Ito et al., 1969), does not block the GABA response in the leech muscle fibers.

\section{Discussion}

The results presented here demonstrate that GABA mediates inhibitory synaptic transmission from the inhibitors to their central targets, the excitors and to their peripheral targets, the longitudinal muscle fibers. In the CNS, direct application of GABA to the postsynaptic targets of the inhibitors and synaptic release of neurotransmitter by the inhibitors both hyperpolarize the excitor membrane. The reversal potential of the GABAactivated channels is about $-63 \mathrm{mV}$. Pharmacological studies of the postsynaptic GABA receptors indicate that bicuculline methiodide, a known GABA antagonist (Pong and Graham, 1972), blocks reversibly the synaptic transmission from inhibitor to excitor. Finally, inhibitory motor neurons exhibit the capacity for GABA synthesis, whereas neurons using other transmitters do not.

Similarly, at the neuromuscular junction, focal application of GABA to an inhibitory region of the muscle fiber causes an increase in membrane conductance and a change in membrane polarization in the same direction as that due to the spontaneous IJPs. The reversal potential of both the GABA response and the spontaneous IJPs is about $-65 \mathrm{mV}$, similar to the reversal potential of the GABA response in the excitors. Previous reports of the reversal potential and ionic dependence of the IJP in muscle fibers of Hirudo (Sawada et al., 1976), indicate that the IJPs in Hirudo are chloride-mediated. Therefore, it is possible that the IJP and GABA response in Haementeria are due to an increased chloride conductance. The GABA receptors of the muscle fibers are blocked reversibly by bicuculline methiodide. No bicuculline-resistant IJPs are recorded from the muscle fibers, suggesting that GABA may be the only inhibitory neu-

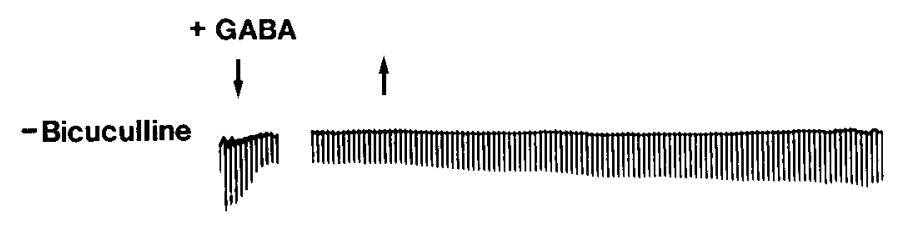

+Bicuculline

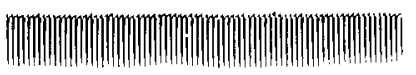

Wash

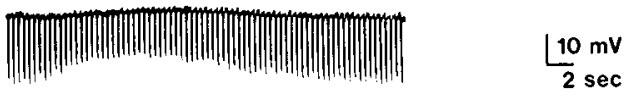

Figure 9. Muscle fiber response to focal application of GABA and the effect of bicuculline methiodide $\left(5 \times 10^{-5} \mathrm{M}\right)$. Focal application of GABA to muscle fibers at sites from which spontaneous IJPs are recorded results in an increase in membrane conductance and polarization (top and bottom traces). The resting potential of the muscle fiber was -70 $\mathrm{mV}$, accounting for the depolarizing response to GABA. The interruption in the top trace represents 2 min of maintained response to continual GABA application. Bicuculline methiodide $\left(5 \times 10^{-5} \mathrm{M}\right.$ in the bathing solution) reversibly blocks the response to GABA.

romuscular transmitter that produces discrete junctional potentials.

\section{The central nervous system}

Electron-microscopic studies reveal no synapses on the cell bodies of leech neurons (Coggeshall and Fawcett, 1964). The inhibitor-excitor synapses are in the neuropil, contralateral to the inhibitor cell body, where the portions of the dendritic arbors from the excitor and inhibitor come into close apposition (Granzow et al., 1985; Macagno et al., 1981). Furthermore, diffusion of GABA through the neuropil is restricted by the high-affinity GABA uptake system (Cline, 1983). The neuropil glial cell surrounds the region of the inhibitor-excitor synapses and ensheaths the dendrites of the motor neurons as a dense web of glial processes (Coggeshall and Fawcett, 1964). Consequently, GABA added to the bathing solution or applied focally to the cell bodies or major neurite probably cannot reach the synaptic GABA receptors, and its effect is a result of activation of extrasynaptic receptors.

\section{Determination of the reversal potential}

The apparent reversal potential of the GABA response was obtained by the unusual method reported here because the excitor membrane exhibits a large anomalously rectifying conductance and because the GABA response at the excitor cell body desensitizes upon repeated application of transmitter (Cline, 1985). Because of these properties, the apparent reversal potential was extrapolated from the cell body response to a single focal application of GABA while hyperpolarizing current in either a fast or slow frequency ramp was injected into the neuron. This method allows one to determine the reversal potential of a rapidly desensitizing membrane response with a single application of transmitter. Furthermore, one can determine the reversal potential of a relatively small conductance by subtracting the dominant conductance.

Figure 6 demonstrates that even though the excitor membrane can be hyperpolarized below $E_{\mathrm{Cl}}$, the difference in membrane potential recorded at any level of current injection is not large, due to the large conductance activated at about $-50 \mathrm{mV}$. The problem of receptor desensitization aside, one can see that it would be difficult to determine reliably an apparent potential for the GABA response by the conventional method 
of polarizing the membrane potential to different potentials and pulsing with GABA, because the differences in response in the absence and presence of GABA are only a few millivolts. By superimposing the responses to the ramp of injected current, the membrane potential range at which the GABA response is flattencd and reversed becomes apparent as the point where the 2 membrane potential recordings cross. A closer estimation of the GABA reversal potential was achieved by injecting rapid ramps of current into the excitor before and during focal GABA application (Fig. 7). Presenting the data as an $I / V$ curve has the advantage of displaying the conductance change due to anomalous rectification as a sudden change in the slope of the curve. Extrapolation from the initial portion of the curves, where the GABA response is clear, yields the apparent reversal potential of the GABA response.

\section{Neurotransmitter synthesis}

Since cultured neurons retain their characteristic electrophysiological membrane properties, extend neurites, and maintain their original neurotransmitter characteristics for up to 3 weeks (Fuchs et al., 1981; Henderson, 1983; Ready and Nicholls, 1979), it seemed likely that their GABA metabolism would reflect the in vivo situation. The capacity for GABA synthesis was found to be present in the inhibitors but not in the excitors, which are presumably cholinergic (Kuffler, 1978; Sargent, 1977), nor in the mechanosensory $\mathbf{P}$ cells, whose transmitter has not been identified. The capacity for GABA synthesis was detected in the Retzius cells, which are known to use 5-HT as a neurotransmitter and/or neurohormone (Glover, 1984; Henderson, 1983; Willard, 1981). Henderson (1983) reported that Retzius cells do not have the capacity to synthesize GABA. The difference in our results probably arises from the different precursor concentrations to which the neurons were exposed. A dose-response curve (Cline, 1983) revealed that isolated ganglia from Hirudo have the capacity to synthesize 1000 times more GABA when exposed to $10 \mathrm{~mm}$ glutamate, used in this study, than when exposed to $0.02 \mathrm{~mm}$ glutamate, used by Henderson. Considering the complex role of the Retzius cells in leech physiology (Glover, 1984; Lent, 1977; Willard, 1981), in particular nerve-muscle interactions (Mason and Kristan, 1982; Mason et al., 1979), it is of interest that the Retzius cells synthesize and release GABA in addition to $5-\mathrm{HT}$.

\section{The neuromuscular junction}

The membrane potential maintained by the muscle fibers in Haementeria is about -70 to $-80 \mathrm{mV}$, below the reversal potential of the IJPs. Therefore, one might expect that the inhibitors can influence muscle tension only in the presence of excitorinduced contractions, rather than by accelerating muscle fiber relaxation or reducing basal tension (Mason and Kristan, 1982).

\section{Complementarity of motor neuron modality and transmitter receptors}

By combining electrophysiological recordings to locate motor neuron terminals on the muscle fibers and focal application of GABA and ACh to locate transmitter receptor sites, the neurotransmitter receptors are observed to be specifically segregated according to the modality of the innervating motor neurons. When GABA is applicd to a sitc from which spontancous IJPs are recorded (and which would therefore be rich in GABA receptors), the typical membrane polarization and conductance increase result. Application of ACh to such a site results in no immediate membrane response. In contrast, a site from which exclusively spontaneous EJPs are recorded (and which would therefore be rich in $\mathrm{ACh}$ receptors) responds to $\mathrm{ACh}$ but not to GABA. Application of either transmitter to a region of the fiber devoid of junctional potentials produces no immediate membrane response, suggesting that there are few extrajunctional receptors for either transmitter. Because of their small diameter, leech muscle fibers probably have a short electrical length constant (Stuart, 1970), such that intracellular electrodes record only activity originating from nearby sites. Therefore, the spatial segregation in both the spontaneous junctional potentials and in the local response to exogenously applicd neurotransmitters reflects a topographic segregation of transmitter receptors along the length of the muscle fiber.

Thus, the present study, as well as those of Stuart (1970) and Sawada et al. (1976), indicates that 2 or more motor neurons of the same modality (i.e., excitatory or inhibitory) may innervate the same fiber, as may 2 or more motor neurons of opposite modalities. The junctional terminals of excitors and inhibitors innervating the same fiber are located at spatially and electrically discrete sites, whereas the junctional terminals of motor neurons of the same modality may be intermingled. A similar pattern of neuromuscular innervation has been found in other annelids (Hidaka et al., 1969) and in crustaceans (Atwood, 1976), in which individual muscle fibers receive excitatory and inhibitory inputs to form spatially distinct neuromuscular junctions (Florey and Cahill, 1982; Takeuchi and Takeuchi, 1965).

The experiments reported here were performed using a ventral nerve cord preparation from Hirudo for studies of the central inhibitory synapses and a body wall preparation from $\mathrm{Hae}$ menteria for the studies of the neuromuscular junction according to the advantages of each species. Previous studies comparing the hirudinid and glossiphoniid leeches indicate that there is a high degree of homology between Hirudo and Haementeria in terms of the function, structure, and neurochemistry of the neurons in the CNS (Cline, 1983; Glover, 1984; Kramer, 1981; Kramer and Goldman, 1981). This study provides another example of the homologies between the 2 leech species.

Although no other inhibitory neurotransmitter has been identified conclusively in the leech CNS, it is likely that GABA is not the only inhibitory neurotransmitter in this system. Intracellular recordings from the excitors reveal a class of IPSPs that persists in the presence of bicuculline methiodide. The reversal potential of the bicuculline-resistent IPSPs appears to be more negative that that of the GABA-elicited IPSPs. Furthermore, not all of the previously identified inhibitory neurons take up GABA (Cline, 1983).

In summary, GABA mediates inhibitory neurotransmission at the central synapse between the inhibitors and the excitors, and at the neuromuscular junction of the longitudinal muscle fibers. GABA hyperpolarizes the excitor or muscle fiber membrane potential by binding to a bicuculline-sensitive receptor. The inhibitors synthesize GABA when exposed to the precursor glutamate and take up GABA from the surrounding medium by a high-affinity uptake system (Cline et al., 1985). Single muscle fibers are innervated at spatially discrete sites by both inhibitory and excitatory motor neurons, and neurotransmitter receptors are segregated along the length of the fiber to complement the modality of the innervating neuron.

\section{References}

Atwood, H. L. (1976) Organization and synaptic physiology of crustacean neuromuscular systems. Prog. Neurobiol. 7: 291-391.

Baylor, D. A., and J. G. Nicholls (1969) Chemical and electrical synaptic connexions between cutaneous mechanoreceptor neurons in the central nervous system of the leech. J. Physiol. (Lond.) 203: 591-609.

Cline, H. T. (1983) ${ }^{3}$ H-GABA uptake selectively labels identifiable neurons in the leech central nervous system. J. Comp. Neurol. 215: 351-358.

Cline, H. T. (1985) GABA-ergic neurons in the leech central nervous system. Ph.D. thesis, University of California, Berkeley.

Cline, H. T., M. P. Nusbaum, and W. B. Kristan, Jr. (1985) Identified GABAergic inhibitory motor neurons in the leech central nervous system take up GABA. Brain Res. 348: 359-362.

Coggeshall, R. E., and D. W. Fawcett (1964) The fine structure of the 
central nervous system of the leech, Hirudo medicinalis. J. Neurophysiol. 27: 229-289.

Florey, E., and M. A. Cahill (1982) The innervation pattern of crustacean skeletal muscle. Morphometry and ultrastructure of terminals and synapses. Cell Tissue Res. 224: 527-541.

Fuchs, P. A., J. G. Nicholls, and D. F. Ready (1981) Membrane properties and selective connexions of identified leech neurons in culture. J. Physiol. (Lond.) 316: 203-223.

Glover, J. C. (1984) Structure, function and development of serotonincontaining neurons in the leech. Ph.D. thesis, University of California, Berkeley.

Granzow, B., W. O. Friesen, and W. B. Kristan, Jr. (1985) Physiological and morphological analysis of synaptic transmission between leech motor neurons. J. Neurosci. 5: 2035-2050.

Hagiwara, S., and L. A. Jaffe (1979) Electrical properties of egg cell membrane. Annu. Rev. Biophys. Bioeng. 81: 385-416.

Henderson, L. P. (1983) The role of 5-hydroxytryptamine as a transmitter between identified leech neurons in culture. J. Physiol. (Lond.) 339: 309-324.

Hidaka, T., Y. Ito, H. Kuriyami, and N. Tashiro (1969) Neuromuscular transmission in the longitudinal layer of somatic muscle in the earthworm. J. Exp. Biol. 50: 417-430.

Hille, B. (1984) Ionic Channels of Excitable Membranes, Sinauer Associates, Sunderland, MA:

Ito, Y., H. Kuriyama, and N. Tashiro (1969) Effects of $\gamma$-aminobutyric acid and picrotoxin on the permeability of the longitudinal muscle of the earthworm to various anions. J. Exp. Biol. 51: 363-375.

Kramer, A. P. (1981) The nervous system of the glossiphoniid leech Haementeria ghilianii. II. Synaptic pathways controlling body wall shortening. J. Comp. Physiol. 144: 449-457.

Kramer, A. P., and J. R. Goldman (1981) The nervous system of the glossiphoniid leech Haementeria ghilianii. I. Identification of neurons. J. Comp. Physiol. 144: 435-448.

Kristan, W. B., Jr., G. S. Stent, and C. A. Ort (1974) Neuronal control of swimming in the medicinal leech. III. Impulse patterns of the motoneurons. J. Comp. Physiol. 94: 155-176.

Kuffler, D. (1978) Neuromuscular transmission in longitudinal muscle of the leech Hirudo medicinalis. J. Comp. Physiol. 124: 333-338.

Latorre, R., R. Coronado, and C. Vergara (1984) $\mathrm{K}^{+}$channels gated by voltage and ions. Annu. Rev. Physiol. 46: 485-495.

Lent, C. M. (1977) The Retzius cells within the central nervous system of leeches. Prog. Neurobiol. 8:81-117.

Macagno, E. R., K. J. Muller, W. B. Kristan, S. A. Deriemer, R. Stewart, and B. Granzow (1981) Mapping of neuronal contacts with intracellular injection of horseradish peroxidase and Lucifer Yellow in combination. Brain Res. 217: 143-149.

Mason, A., and W. B. Kristan, Jr. (1982) Neuronal excitation, inhibition and modulation of leech longitudinal muscle. J. Comp. Physiol. 146: 527-536.

Mason, A., A. J. Sunderland, and L. D. Leake (1979) Effects of leech Retzius cells on body wall muscles. Comp. Biochem. Physiol. 63C: 359-361.

Muller, K. J., J. G. Nicholls, and G. S. Stent (1981) Neurobiology of the Leech, Cold Spring Harbor Laboratory, Cold Spring, NY.
Nicholls, J. G., and D. Purves (1970) Monosynaptic chemical and electrical connexions between sensory and motor cells in the central nervous system of the leech. J. Physiol. (Lond.) 209: 547-567.

Nicholls, J. G., and B. G. Wallace (1978) Modulation of transmission at an inhibitor synapse in the central nervous system of the leech. $J$. Physiol. (Lond.) 281: 157-170.

Ort, C. A., W. B. Kristan, Jr., and G. S. Stent (1974) Neuronal control of swimming in the medicinal leech. II. Identification and connections of motor neurons. J. Comp. Physiol. 94: 121-154.

Otsuka, M. (1976) GABA in the crustacean nervous system: A historical review. In GABA in Nervous System Function, E. R. Roberts, T. N. Chase, and D. B. Towcr, cds., pp. 245-249, Raven, New York.

Pong, S. F., and L. T. Graham, Jr. (1972) N-methyl bicuculline, a convulsant more potent than bicuculline. Brain Res. 42: 486-490.

Poon, M. (1976) Neuronal network generating the swimming rhythm of the leech. Ph.D. thesis, University of California, Berkeley.

Ready, D. F., and J. G. Nicholls (1979) Identified neurons isolated from the leech CNS make selective connections in culture. Nature 182: 67-69.

Sargent, P. B. (1977) Synthesis of acetylcholine by excitatory motoneurons in the central nervous system of the leech. J. Neurophysiol. 40: 453-460.

Sawada, M., and R. E. Coggeshall (1976) Ionic mechanisms of 5 -hydroxytryptamine-induced hyperpolarization and inhibitory junctional potential in body wall muscle cells of Hirudo medicinalis. J. Neurobiol. 7: 63-67.

Sawada, M., J. M. Wilkenson, D. J. McAdoo, and R. E. Coggeshall (1976) The identification of two inhibitory cells in each segmental ganglion of the leech and studies on the ionic mechanism of the inhibitory junctional potentials produced by these cells. J. Neurobiol. 7: 435-445.

Sawyer, R. T., F. LePont, D. K. Stuart, and A. P. Kramer (1981) Growth and reproduction of the giant glossiphoniid leech Haementeria ghilianii. Biol. Bull. 160: 322-331.

Schousboe, A. (1981) Transport and metabolism of glutamate and GABA in neurons and glial cells. Int. Rev. Neurobiol. 22: 1-45.

Stent, G. S., W. B. Kristan, Jr., W. O. Friesen, C. A. Ort, M. Poon, and R. L. Calabrese (1978) Neuronal generation of the leech swimming movement. Science 200: 1348-1356.

Stent, G. S., W. J. Thompson, and R. L. Calabrcsc (1979) Neuronal control of heartbeat in the leech and some other invertebrates. Physiol. Rev. 59: 101-136.

Stuart, A. E. (1970) Physiological and morphological properties of motoneurons in the central nervous system of the leech. J. Physiol. (Lond.) 209: 627-646.

Takeuchi, A., and N. Takeuchi (1965) Localized action of gammaaminobutyric acid on neuromuscular transmission in the crayfish. J. Physiol. (Lond.) 177: 225-238.

Weeks, J. C. (1982) Synaptic basis of swim initiation in the leech. II. A pattern-generating neuron (Cell 208) which mediates motor effects of swim-initiating neurons. J. Comp. Physiol. 148: 265-279.

Willard, A. L. (1981) Effects of serotonin on the generation of the motor pattern for swimming by the medicinal leech. J. Neurosci. 1: 936-944. 